\title{
Transmission of SARS-CoV-2 considering shared chairs in outpatient dialysis: a real- world case-control study
}

\author{
Ravi Thadhani ${ }^{1}$, Joanna Willetts ${ }^{2}$, Catherine Wang ${ }^{3}$, John Larkin ${ }^{2 *}$, Hanjie Zhang ${ }^{4}$, Lemuel Rivera Fuentes ${ }^{4}$, \\ Len Usvyat ${ }^{2}$, Kathleen Belmonte ${ }^{5}$, Yuedong Wang ${ }^{6}$, Robert Kossmann ${ }^{7}$, Jeffrey Hymes ${ }^{2}$, Peter Kotanko $0^{4,8}$ and \\ Franklin Maddux ${ }^{9}$
}

\begin{abstract}
Background: SARS-CoV-2 can remain transiently viable on surfaces. We examined if use of shared chairs in outpatient hemodialysis associates with a risk for indirect patient-to-patient transmission of SARS-CoV-2.

Methods: We used data from adults treated at 2,600 hemodialysis facilities in United States between February 1st and June 8th, 2020. We performed a retrospective case-control study matching each SARS-CoV-2 positive patient (case) to a non-SARS-CoV-2 patient (control) treated in the same dialysis shift. Cases and controls were matched on age, sex, race, facility, shift date, and treatment count. For each case-control pair, we traced backward 14 days to assess possible prior exposure from a 'shedding' SARS-CoV-2 positive patient who sat in the same chair immediately before the case or control. Conditional logistic regression models tested whether chair exposure after a shedding SARS-CoV-2 positive patient conferred a higher risk of SARS-CoV-2 infection to the immediate subsequent patient.

Results: Among 170,234 hemodialysis patients, 4,782 (2.8\%) tested positive for SARS-CoV-2 (mean age 64 years, $44 \%$ female). Most facilities (68.5\%) had 0 to 1 positive SARS-CoV-2 patient. We matched 2,379 SARS-CoV-2 positive cases to 2,379 non-SARS-CoV-2 controls; $1.30 \%$ (95 \%Cl 0.90\%, $1.87 \%$ ) of cases and $1.39 \%$ (95\%Cl $0.97 \%, 1.97 \%)$ of controls were exposed to a chair previously sat in by a shedding SARS-CoV-2 patient. Transmission risk among cases was not significantly different from controls $(\mathrm{OR}=0.94 ; 95 \% \mathrm{Cl} 0.57$ to $1.54 ; \mathrm{p}=0.80)$. Results remained consistent in adjusted and sensitivity analyses.
\end{abstract}

Conclusions: The risk of indirect patient-to-patient transmission of SARS-CoV-2 infection from dialysis chairs appears to be low.

Keywords: Hemodialysis, Kidney Failure, End Stage Renal Disease, SARS-CoV-2, COVID-19

\footnotetext{
* Correspondence: John.Larkin@fmc-na.com

${ }^{2}$ Fresenius Medical Care, Global Medical Office, 920 Winter Street, Waltham,

MA, USA

Full list of author information is available at the end of the article
}

(c) The Author(s). 2021 Open Access This article is licensed under a Creative Commons Attribution 4.0 International License, which permits use, sharing, adaptation, distribution and reproduction in any medium or format, as long as you give appropriate credit to the original author(s) and the source, provide a link to the Creative Commons licence, and indicate if changes were made. The images or other third party material in this article are included in the article's Creative Commons licence, unless indicated otherwise in a credit line to the material. If material is not included in the article's Creative Commons licence and your intended use is not permitted by statutory regulation or exceeds the permitted use, you will need to obtain permission directly from the copyright holder. To view a copy of this licence, visit http://creativecommons.org/licenses/by/4.0/ The Creative Commons Public Domain Dedication waiver (http://creativecommons.org/publicdomain/zero/1.0/) applies to the data made available in this article, unless otherwise stated in a credit line to the data. 


\section{Background}

Hemodialysis is a lifesaving therapy for individuals with end-stage kidney disease (ESKD). Most ESKD patients are treated in an outpatient setting and require thrice weekly maintenance hemodialysis. Unlike other medical procedures that were canceled or postponed during the initial surge of COVID-19 cases, hemodialysis treatments continued during this period and will continue throughout any subsequent outbreak [1-3]. The pandemic has highlighted several population-specific vulnerabilities to increased mortality risk, including older age, non-white race, and presence of underlying conditions such as diabetes, obesity, cardiovascular disease, and ESKD requiring maintenance hemodialysis [4-7]. Because individuals with ESKD are known to have immunologic deficiencies [8] and higher frequencies of the very same risk factors that predispose humans to adverse outcomes following SARS-CoV-2 infection, their risk for adverse outcomes is compounded [9-12].

During the pandemic start, outpatient dialysis facilities worldwide implemented enhanced infection control measures to limit transmission of SARS-CoV-2 [13-15]. In the United States, mitigation strategies adopted by a national dialysis network included screening before and universal masking while in facility, testing of patients/ staff with flu-like symptoms, as well as designating isolation shifts/facilities [16]. While the primary mode of person-to-person transmission of the SARS-CoV-2 virus is through aerosolized droplets, $[17,18]$ the virus can deposit and remain transiently viable on surfaces, and surface-to-individual transmission represents yet another opportunity for infection [19-21].

In the United States, outpatient hemodialysis facilities usually accommodate up to 40 chairs/stations per site. Hemodialysis sessions occur in shifts, and each dialysis station (dialysis machine and corresponding chair) in each facility generally accommodates approximately four successive patients each day with dialysis station surfaces cleaned between treatments. Given SARS-CoV-2 may be transmitted while infected individuals remain asymptomatic for several days, [22] we sought to examine transmission dynamics within facilities, with a specific focus on possible indirect transmission through shared dialysis chairs while infected patients were still asymptomatic yet likely shedding the virus (i.e. before symptoms or testing SARS-CoV-2 positive). Our primary hypothesis was that chair exposure does not confer a higher risk to the patient sitting on the same chair immediately after an infected patient.

\section{Methods}

\section{Participants}

We used data from all adult (age $\geq 18$ years) in-center hemodialysis patients treated at the national network of dialysis clinics (Fresenius Kidney Care (FKC), Waltham, MA, United States) between February 1, 2020 and June 8 , 2020. Patient data were de-identified using the Safe Harbor method for analysis, [23] which was performed under a regulatory protocol reviewed by New England Institutional Review Board (Needham Heights, MA, United States; NEIRB WO\#: 17-1349084-1); the analysis was approved under Exempt Category (45 CFR 46.104d4ii) and consent was not required. The Safe Harbor deidentification method included removal of 18 types of identifiers per Sec. 164.514(b)(2) of the United States Health Insurance Portability and Accountability Act of 1996 Privacy Rule and randomly assigned patient/facility identification numbers were used for analysis purposes. Analysis was conducted in adherence with Declaration of Helsinki.

\section{Clinic SARS-CoV-2 Screening and Testing Practices}

The national dialysis provider identified the first patients $(\mathrm{n}=2)$ with SARS-CoV-2 on March 3, 2020. Since late February 2020, the provider universally adopted modified mitigation measures in response to the pandemic, which included documented screening prior to admittance for patients, staff, and people entering the facility. Patients were provided with and required to wear a surgical face mask during screening and while in facility. Dialysis staff were required to wear surgical face masks, face shields, gowns, and gloves during direct patient care.

Trained healthcare screeners asked standardized questions regarding flu-like symptoms (e.g., fever, respiratory symptoms), recent travel, close-contact to people with COVID-19. Patients/staff without signs/symptoms were admitted. Any patients/staff who presented with signs/symptoms of a flu-like illness or had a body temperature $\geq 37.8{ }^{\circ} \mathrm{C}$ failed screening.

Symptomatic patients had their treatments moved to isolation shifts dedicated to persons under investigation (PUI) where staff universally performed nasopharyngeal swabs for SARS-CoV-2 RT-PCR testing. Any patients who failed screening due to recent exposure to someone with COVID-19 were moved into unique isolation shifts apart from symptomatic PUI shifts, if possible. If exposed patients presented with flu-like symptoms while under 14 days of isolation, they were moved to a PUI isolation shift and received RT-PCR testing. PUIs testing SARS-CoV-2 positive were moved to dedicated COVID19 shifts. PUI and SARS-CoV-2 positive patients were required to have two negative RT-PCR tests $>24 \mathrm{~h}$ apart to return to the general hemodialysis population. Isolation facilities or shifts were designated based on the number of suspected/confirmed SARS-CoV-2 patients in geographies. Similar processes were implemented for facility staff; symptomatic/exposed staff were required to 
quarantine at home, symptomatic staff received RT-PCR testing and were required to have negative test results or be cleared by their healthcare provider before returning to work.

\section{Facility Infection Control Procedures}

Per the provider's standard disinfection protocol, chairs and outside surfaces of the hemodialysis machine are cleaned between patients using 1:100 bleach; this applies to general and isolation shifts. Internal components of dialysis machines are cleaned according to company policy and CDC guidelines [24], which includes daily acid (i.e. vinegar) and heat disinfection and weekly bleach disinfection. Cleaning procedures take place between successive treatments (average of $90 \pm 68 \mathrm{~min}$ between patients in study period). Patient facing rooms (e.g., lobby, restroom) are thoroughly cleaned during dialysis shift changes.

\section{Dialysis Station Designation}

The machine and station number used for each hemodialysis treatment was documented in electronic medical record. Station number indicates the physical location in the facility where treatment occurs. Chairs are not numbered, however, they are generally not moved from one physical station to another other than: First, if a patient weighs $>350$ pounds ( $>159 \mathrm{~kg}$ ), a special chair is allotted; Second, if a patient had a bleeding episode, a chair may be moved for enhanced cleaning; Third, if a chair breaks during a treatment, a different chair will be assigned; Finally, prior to SARS-CoV-2 outbreak, floors were periodically waxed, hence chairs may have been moved. Examining frequencies of other scenarios that would 'disconnect' the chair from the dialysis station yielded insignificant occurrences. Therefore, station number was used as a proxy for chair number with several sensitivity analyses conducted to confirm findings.

\section{Statistical Analyses}

We considered two main designs to investigate whether shared chairs associate with a risk of indirect SARS-CoV-2 transmission: a retrospective case-control analysis and a prospective cohort analysis. Given the infrequent incidence of SARS-CoV-2, we chose to use a case-control design for the primary analysis because of its suitability in studying rare events and due to the ability to use data from all eligible patients. We also performed a confirmatory prospective cohort analysis considering only the first chair in each facility sat in by a shedding SARS-CoV-2 patient and anticipated a smaller patient group.

Therefore, our primary analysis used a retrospective case-control design [25], where each SARS-CoV-2 patient (case) was matched with a non-SARS-CoV-2 patient (control) in the same shift (Fig. 1). The exposure was defined as hemodialysis in a chair immediately after a SARS-CoV-2 positive patient sat in the same chair during a 'shedding period'. For a matched case-control pair, the 'shedding period' was defined as -3 days before to +7 days after the earliest recorded SARS-CoV-2 presentation or test date; this was the estimated timeframe in which a positive patient or 'donor' may have spread SARS-CoV-2 to the next patient that sat in the chair $[26,27]$. The 'shedding period' window was chosen considering some reports were missing symptom date (only SARS-CoV-2 positive test date), as well as the possibility of a recall bias in recorded symptom date. We performed sensitivity analyses around this window to reduce the likelihood this assumption influenced results. In all analyses we confirmed the 'donor' patient was treated in the chair and was not yet transferred to an isolation shift/facility.

The exposure period for a non-SARS-CoV-2 'recipient' patient was defined as -14 days to -1 day before each 'donor' patient's 'shedding period' (Fig. 1); this was the estimated timeframe in which a 'recipient' patient could have contracted SARS-CoV-2 from sitting in a chair after a 'donor' patient [28]. In all analyses, we excluded data from isolation shifts/facilities, as well as treatments from the first SARS-CoV-2 patient(s) in each facility who would not have had a known opportunity to contract the virus from exposure at the facility. Furthermore, facilities with $<200$ treatments during the observation period were excluded as it indicated the facility was newly opened or closed, precluding a thorough analysis of potential for transmission.

For each SARS-CoV-2 positive patient (case), we identified their most recent dialysis treatment during their exposure period, identified non-SARS-CoV-2 patients who were treated in that same facility on that day, and then selected a control as the patient who has the best match with the case based on shift time, number of treatments during exposure period, gender, age, and race, in that hierarchical order (Fig. 1).

We fitted four conditional logistic regression models: Model 1: exposure status only; Model 2: in addition to Model 1, age, dialysis vintage, sex, race; Model 3: in addition to Model 2, body mass index (BMI), central venous catheter (CVC) dialysis access, diabetes, chronic obstructive pulmonary disease (COPD); Model 4: in addition to Model 3, county-level 2018 Five-Year Median Household Income and Gini Coefficient (a ratio of household inequality ranging from 0 (complete income equality) to 1 (complete income inequality) [29-31]. County-level data on the Median Household Income and Gini Coefficient was obtained from United States Census Bureau American Community Survey [32, 33]. Analyses were performed using R 3.6.0 (R Foundation 


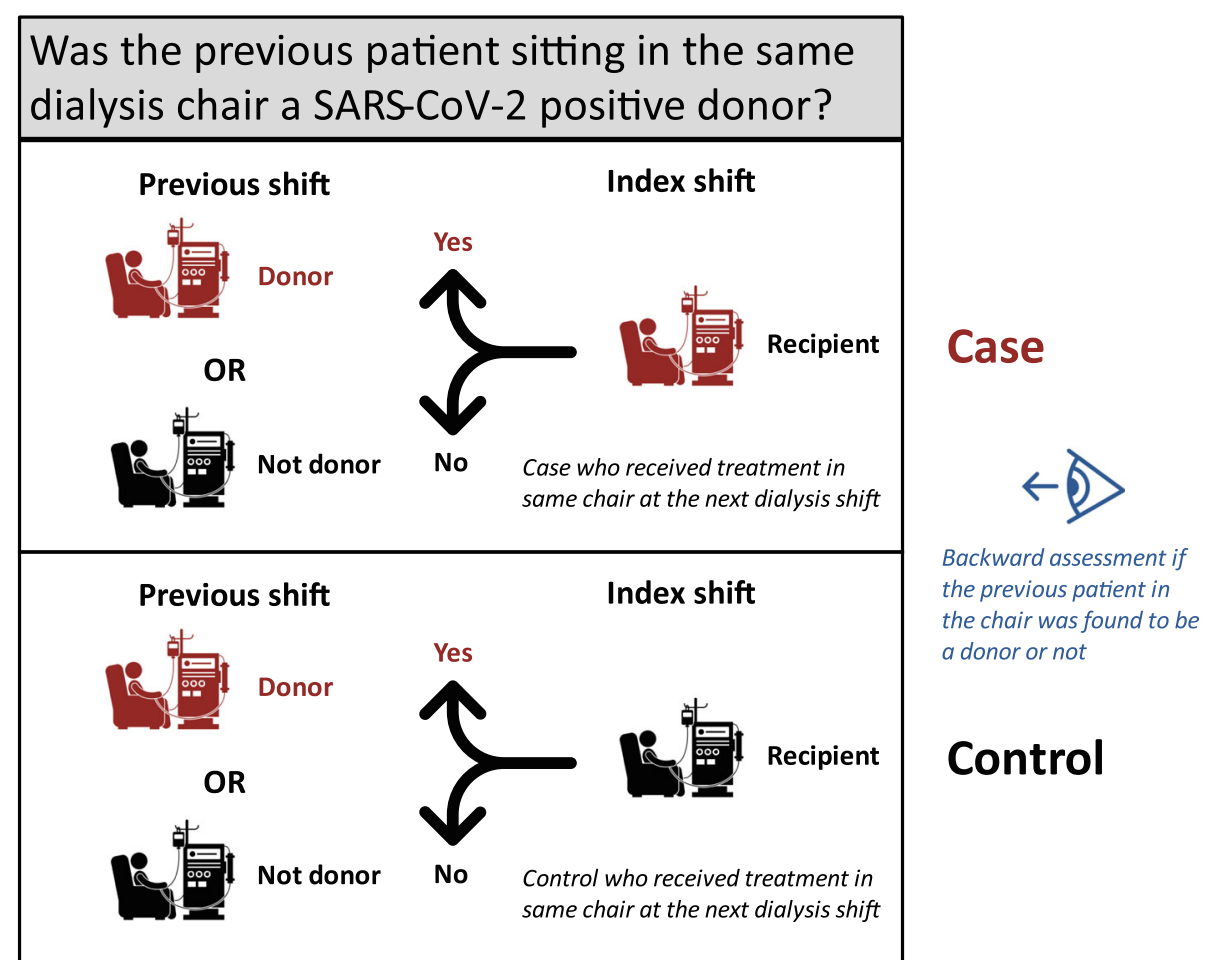

Fig. 1 Depiction of the study design for the retrospective case-control analysis. Each case-control pair at the index shift had a backward assessment to determine if the patient who received dialysis in the previous shift was found to be a COVID-19 positive donor (dialysis station in red) or not (dialysis station in black)

for Statistical Computing, Vienna, Austria). The R package survival was used to fit conditional logistic regression models.

We performed sensitivity analyses that varied the definitions of 'shedding period' and 'exposure period.' The 'shedding period' was modified to -3 days before to +3 days after the recorded SARS-CoV-2 date and to -5 before to + 10 days after the recorded SARS-CoV-2 date. The exposure period was modified to -14 days before to -3 days before the recorded SARS-CoV-2 date.

As a secondary analysis, we performed a prospective analysis. For each facility we identified the first chair occupied by a shedding SARS-CoV-2 patient and labeled other chairs in the same shift of the same facility on the same day as non-SARS-CoV-2 chairs. We then identified patients who sat in SARS-CoV-2 and non-SARS-CoV-2 chairs during the next shift and recorded the proportion of patients who subsequently developed SARS-CoV-2 within 14 days. Finally, we tested whether there was a difference in the proportion of patients with confirmed SARS-CoV-2 in the next 14 days between those who occupied SARS-CoV-2 chairs compared to non-SARS-CoV-2 chairs.

\section{Results}

We considered data from 170,234 adult hemodialysis patients treated at 2,600 outpatient facilities for matching and identification of case-control pairs (Fig. 2). Among 636,758 total dialysis shifts examined, 8,948 (1.41\%) shifts had at least one SARS-CoV-2 patient. Percent of facilities with $0,1,2$, and $\geq 3$ SARS-CoV-2 positive patients was $48.3 \%, 20.2 \%, 10.0 \%$, and $21.5 \%$, respectively (Fig. 3). SARS-CoV-2 patients were on average 64 years old, $44 \%$ were female, and undergoing hemodialysis for approximately 4 years (Table 1 ). There was a higher proportion of SARS-CoV-2 patients with a Black race and diabetes. Hospitalizations occurred in $72.5 \%$ (3466/ 4782) of SARS-CoV-2 positive patients compared to $28.3 \%(46,796 / 165,452)$ of those who tested negative, or never had flu-like symptoms and were not tested.

We identified matches between 2,379 cases and 2,379 controls in 753 facilities (Table 1). Among matched cases-control pairs, $1.30 \%$ (95\%CI $0.90 \%, 1.87 \%$ ) of cases and $1.39 \%$ (95\%CI $0.97 \%, 1.97 \%$ ) of controls had exposure to a chair previously sat in by a shedding SARS-CoV-2 patient. This risk of exposure to a SARSCoV-2 chair was not statistically different in cases compared to controls $(\mathrm{OR}=0.94,95 \% \mathrm{CI} 0.57,1.54, \mathrm{p}=$ 0.80 ), and results remained consistent after adjusting for potential confounding factors (Fig. 4 and Table 2).

We then performed a series of sensitivity analyses, first modifying the 'shedding period' and then modifying the 'exposure period.' Modifying the 'shedding period' of the 


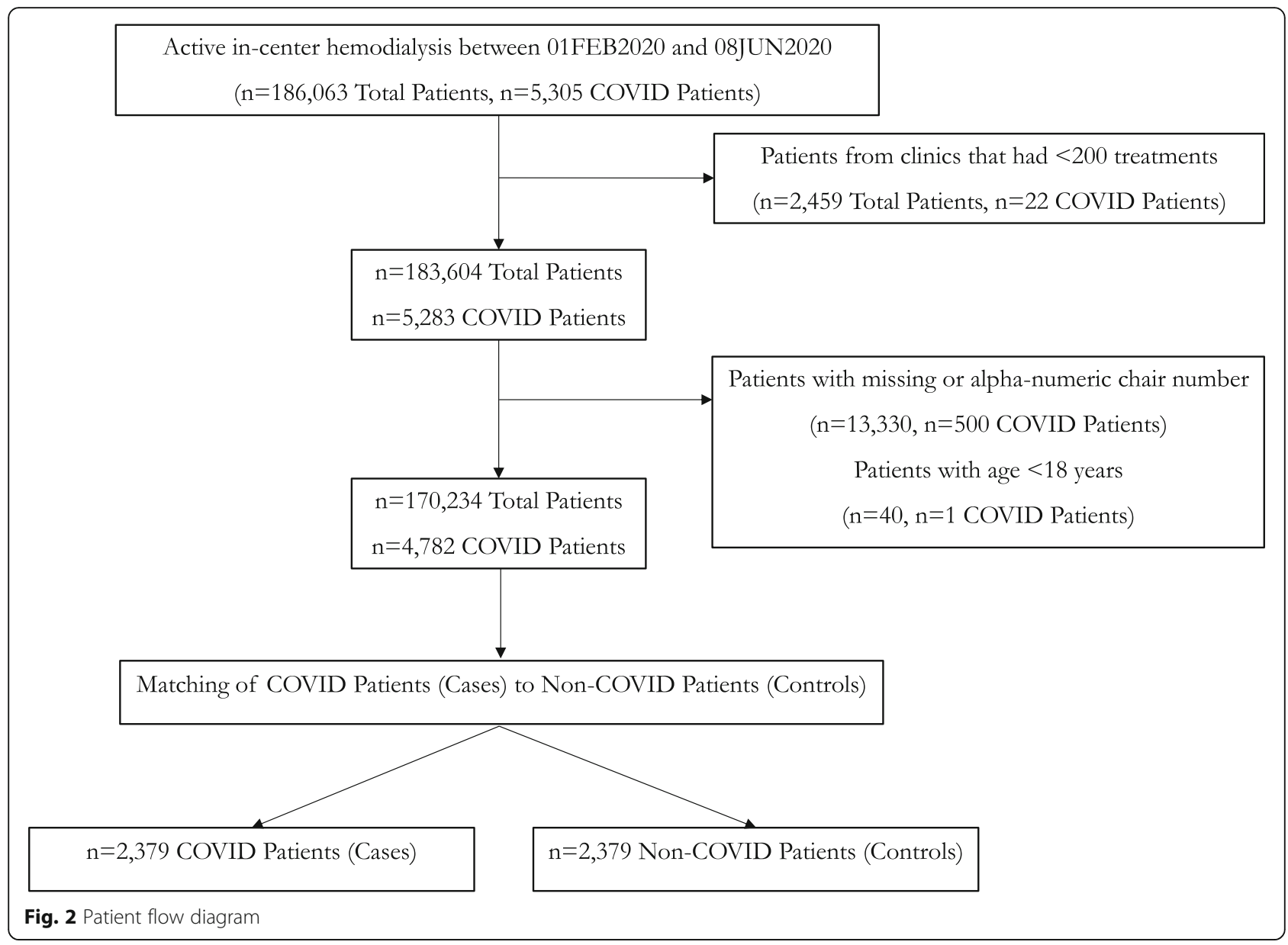

donor patient to -3 days before to +3 days after the recorded SARS-CoV-2 date, we identified 2,370 matched case-control pairs; $1.22 \%$ (95 \%CI $0.84 \%, 1.78 \%$ ) of cases and $1.22 \%(95 \% \mathrm{CI} 0.84 \%, 1.78 \%)$ of controls had exposure to a chair sat by a shedding SARS-CoV-2 patient (estimates were identical). Exposure risk between cases and controls was not significant $(\mathrm{OR}=1.00$, $95 \%$ CI $0.59,1.69, p=1.00$ ). Modifying the 'shedding period' of the donor patient to -5 days before to +10 days after the recorded SARS-CoV-2 date, we identified 2,516 matched case-control pairs, $2.34 \%$ (95 \%CI $1.80 \%$, $3.04 \%$ ) of cases and $2.38 \%$ (95 \%CI $1.84 \%, 3.08 \%$ ) of controls had exposure to a chair sat on by a shedding SARS-CoV-2 patient. Exposure risk did not differ between cases and controls $(\mathrm{OR}=0.98,95 \% \mathrm{CI} 0.68,1.42$, $p=0.92$ ). Finally, modifying the 'recipients' 'exposure period' from -14 to -3 days before the recorded SARSCoV-2 date, we identified 2,335 matched case-control pairs; $1.24 \%$ (95\%CI $0.85 \%, 1.80 \%)$ of cases and $1.28 \%$ ( $95 \%$ CI $0.88 \%, 1.85 \%$ ) of controls had exposure to a chair sat in by a shedding SARS-CoV-2 patient. Exposure risks between cases and controls was not different
$(\mathrm{OR}=0.97,95 \%$ CI $0.57,1.62, p=0.89)$. No results of sensitivity analyses materially changed when adjusted for various confounders.

Finally, we examined exposure risk prospectively. Among 343 and 4552 patients who sat in the next shift in a SARS-CoV-2 chair and a non-SARS-CoV-2 chair, respectively, and $2(0.58 \%)$ and $42(0.92 \%)$ contracted SARS-CoV- 2 in the following 14 days $\left(x^{2}=0.1197, p=\right.$ $0.73)$. The estimated odds ratio for the transmission of SARS-CoV-2 from a chair was 0.63 (95\% CI 0.15, 2.61).

\section{Discussion}

Transmission of SARS-CoV-2 attached to inanimate surfaces is a justified concern since the virus can remain viable on surfaces [19]. Routine capture of real-world data at a national network of outpatient hemodialysis facilities afforded a unique opportunity for examination of transmission between patients in a closed medical environment. Hemodialysis patients sit for approximately $3-5 \mathrm{~h}$ in chairs during thrice weekly sessions. While strict and highly standardized cleaning procedures are in place, there are concerns about possible transmission of SARS- 


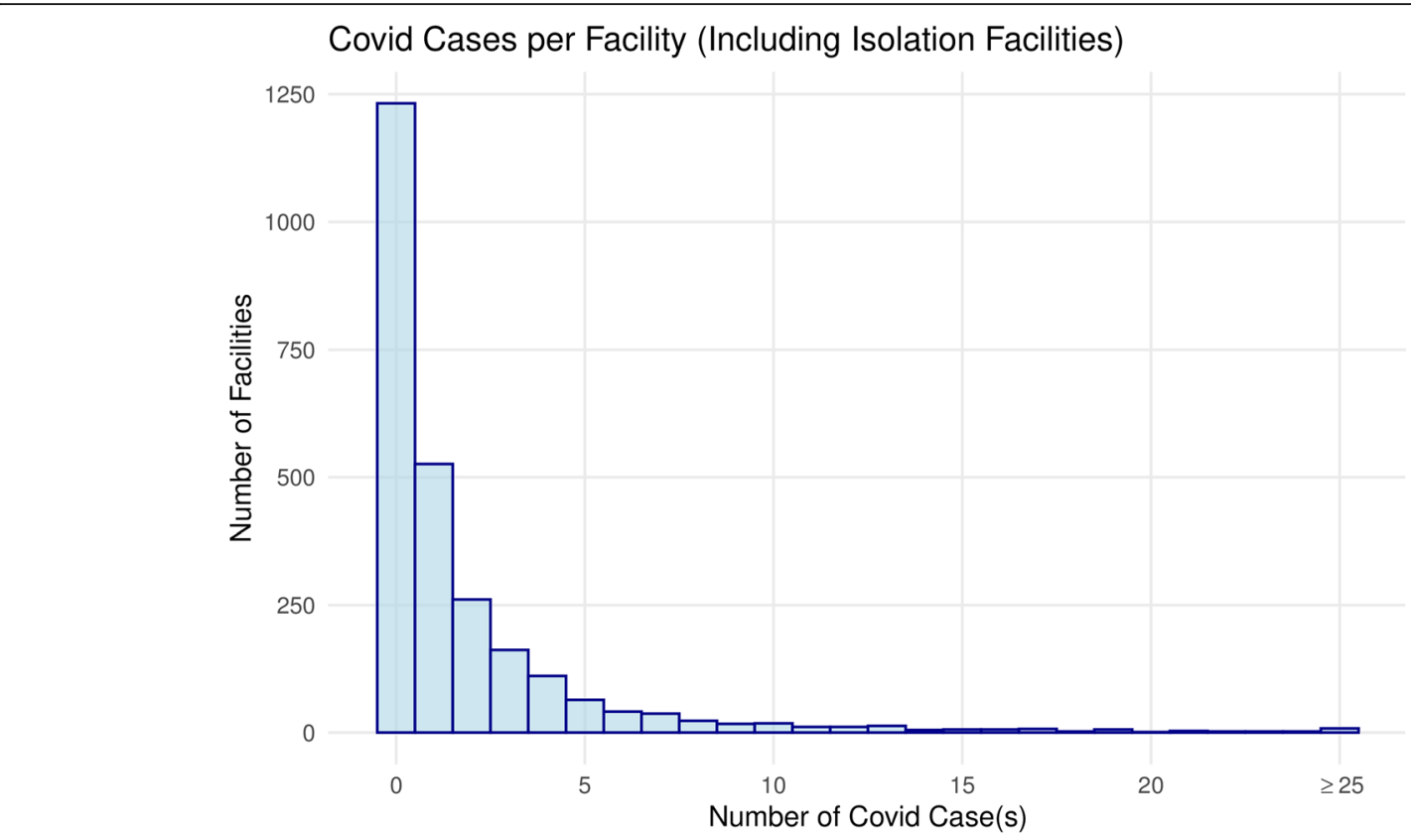

Fig. 3 Histogram of number of COVID-19 cases per facility. ${ }^{a}$ Clinics with $<200$ treatments were excluded as it indicates newly opened or closed clinic; a clinic with one patient would have $\sim 50$ dialysis treatments during this period. ${ }^{b}$ Given that station number is a manually entered field, we chose to exclude clinics that had alpha-numeric station locations that represent entry errors since numeric station numbers are considered standard practice

Table 1 Hemodialysis patient characteristics overall and after case-control matching by COVID-19 status during study period

\begin{tabular}{|c|c|c|c|c|c|c|}
\hline \multirow[b]{3}{*}{ Total Patients } & \multicolumn{4}{|c|}{ Full Patient Population } & \multicolumn{2}{|c|}{ Matched Case and Control Patients } \\
\hline & All Patients & $\begin{array}{l}\text { COVID } \\
\text { Negative }\end{array}$ & $\begin{array}{l}\text { COVID } \\
\text { Positive }\end{array}$ & $p$-value $e^{a, b}$ & $\begin{array}{l}\text { COVID Negative } \\
\text { Controls }\end{array}$ & $\begin{array}{l}\text { COVID } \\
\text { Positive Cases }\end{array}$ \\
\hline & 170,234 & 165,452 & 4,782 & & 2,379 & 2,379 \\
\hline Mean Age at study start $(y \mathrm{r}, \mathrm{sd})^{\mathrm{a}}$ & $63.5(14.2)$ & $63.5(14.2)$ & $64.3(13.8)$ & 0.0002 & $63.7(12.9)$ & $64.2(13.8)$ \\
\hline Mean Time on Dialysis at study start $(y r, s d)^{a}$ & $4.2(4.1)$ & $4.2(4.1)$ & $4.3(4.0)$ & 0.0569 & $4.2(4.1)$ & $4.4(4.1)$ \\
\hline \multicolumn{7}{|l|}{$\operatorname{Sex}^{\mathrm{b}}$} \\
\hline Male (\%) & $97,688(57)$ & $94,991(57)$ & $2,697(56)$ & 0.1633 & $1,334(56)$ & $1,345(57)$ \\
\hline Female (\%) & $72,546(43)$ & $70,461(43)$ & $2,085(44)$ & 0.1633 & $1,045(44)$ & $1,034(43)$ \\
\hline \multicolumn{7}{|l|}{ Race $^{\mathrm{b}}$} \\
\hline White (\%) & $72,578(43)$ & $70,736(43)$ & $1,842(39)$ & $<0.0001$ & $888(37)$ & $888(37)$ \\
\hline Black (\%) & $46,060(27)$ & $44,455(27)$ & $1,605(34)$ & $<0.0001$ & $848(36)$ & $833(35)$ \\
\hline Other (\%) & $6,720(4)$ & $6,579(4)$ & $141(3)$ & 0.0003 & $75(3)$ & $70(3)$ \\
\hline Unknown (\%) & $44,876(26)$ & $43,682(26)$ & $1,194(25)$ & 0.0266 & $568(24)$ & $588(25)$ \\
\hline BMI $\left(\mathrm{kg} / \mathrm{m}^{2}, \mathrm{sd}\right)^{\mathrm{a}}$ & $29.9(7.7)$ & $29.9(7.7)$ & $29.9(7.9)$ & 0.7699 & $29.1(7.1)$ & $29.8(7.9)$ \\
\hline CVC used during study $(\%)^{\mathrm{b}}$ & $30,077(18)$ & $29,112(17)$ & $965(20)$ & $<0.0001$ & $395(17)$ & $450(19)$ \\
\hline Diabetes $(\%)^{\mathrm{b}}$ & $70,745(42)$ & $68,525(41)$ & $2,220(46)$ & $<0.0001$ & $964(41)$ & $1,119(47)$ \\
\hline COPD Diagnosis $(\%)^{\mathrm{b}}$ & $16,331(10)$ & $15,874(10)$ & $457(10)$ & 0.9305 & $202(8)$ & $211(9)$ \\
\hline $\begin{array}{l}\text { Mean Number of Treatments Per Patient } \\
\text { during study period (sd) }\end{array}$ & $48(13)$ & $48(13)$ & $42(12)$ & $<0.0001$ & $49(8)$ & $43(11)$ \\
\hline Five Year Median HH Income (sd) ${ }^{a}$ & $\$ 58,702(16,596)$ & $\$ 58,530(16,519)$ & $\$ 64,627(18,102)$ & $<0.0001$ & $\$ 65,563(18,159)$ & $\$ 65,534(18,416)$ \\
\hline Five Year Gini Coefficient $(s d)^{a}$ & $0.47(0.03)$ & $0.47(0.03)$ & $0.48(0.04)$ & $<0.0001$ & $0.48(0.04)$ & $0.48(0.04)$ \\
\hline
\end{tabular}

${ }^{a}$ For continuous variables, $p$-values result from two-sided t-test $\mathrm{H}_{0}$ : mean values for COVID negative patients are equal to mean values for COVID positive patients in the full population

${ }^{b}$ For categorical variables, $p$-values result from Chi-Square test $\mathrm{H}_{0}$ : proportion in COVID negative patients is equal to proportion in COVID positive patients $B M I$ Body mass index; CVC central venous catheter; COPD chronic obstructive pulmonary disease; HH household; $y r$ year; $s d$ standard deviation 


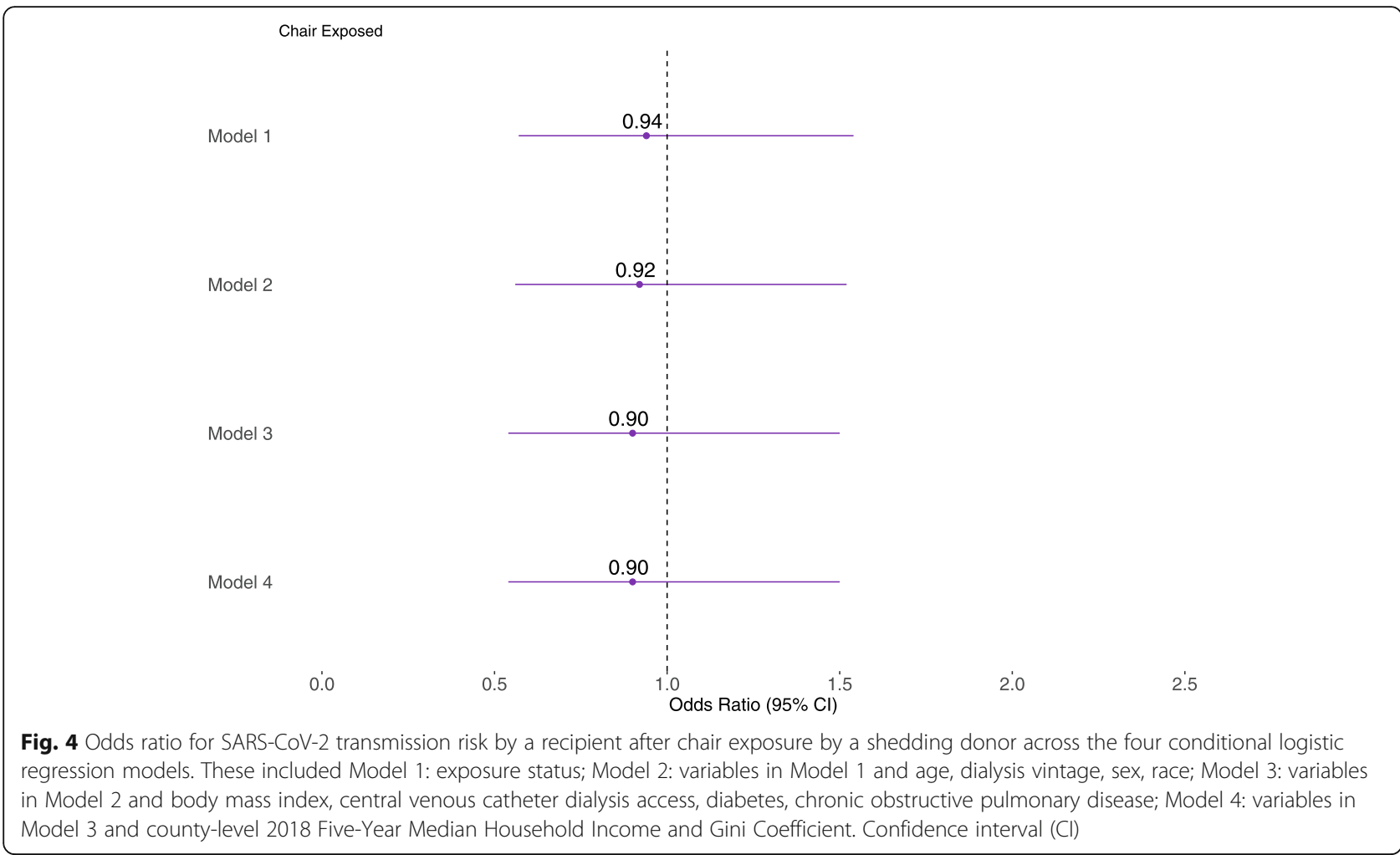

CoV-2 from an infected patient to the dialysis station (chair and/or machine) and from there to the next patient. Our analysis assessed SARS-CoV-2 transmission risk in patients dialyzed at the same station immediately after an infected patient. Our results indicate dialysis chairs and their corresponding machines are unlikely intermediate vectors of patient-to-patient transmission.

SARS-CoV-2 can remain viable on inanimate surfaces depending on temperature, humidity, and material. On polypropylene plastics and stainless steel, the virus can

Table 2 Four conditional logistic regression model results

\begin{tabular}{|c|c|c|c|c|c|c|c|c|}
\hline & \multicolumn{2}{|l|}{ Model 1} & \multicolumn{2}{|l|}{ Model 2} & \multicolumn{2}{|l|}{ Model 3} & \multicolumn{2}{|l|}{ Model 4} \\
\hline & OR $(95 \% \mathrm{Cl})$ & $p$-value & OR $(95 \% \mathrm{Cl})$ & $p$-value & OR $(95 \% \mathrm{Cl})$ & $p$-value & OR $(95 \% \mathrm{Cl})$ & $p$-value \\
\hline Exposed & $0.94(0.57,1.54)$ & 0.7995 & $0.92(0.56,1.52)$ & 0.7435 & $0.90(0.54,1.50)$ & 0.6900 & $0.90(0.54,1.50)$ & 0.6893 \\
\hline Age at Start (yr) & & & $1.01(1.00,1.01)$ & 0.0495 & $1.01(1.00,1.02)$ & 0.0285 & $1.01(1.00,1.02)$ & 0.0290 \\
\hline Vintage at Start (yr) & & & $1.02(1.01,1.04)$ & 0.0050 & $1.03(1.01,1.04)$ & 0.0007 & $1.03(1.01,1.04)$ & 0.0008 \\
\hline Male & & & $1.03(0.91,1.17)$ & 0.6054 & $1.05(0.93,1.19)$ & 0.4177 & $1.05(0.93,1.19)$ & 0.4207 \\
\hline Race is Black (Reference) & & & 1 & & 1 & & 1 & \\
\hline Race is Other & & & $0.98(0.68,1.41)$ & 0.9149 & $1.07(0.74,1.55)$ & 0.7133 & $1.08(0.74,1.56)$ & 0.6903 \\
\hline Race is Unknown & & & $1.16(0.97,1.39)$ & 0.1021 & $1.18(0.98,1.42)$ & 0.0777 & $1.18(0.98,1.42)$ & 0.0776 \\
\hline Race is White & & & $1.05(0.89,1.23)$ & 0.5687 & $1.05(0.90,1.24)$ & 0.5219 & $1.06(0.90,1.24)$ & 0.4997 \\
\hline BMI & & & & & $1.01(1.01,1.02)$ & 0.0010 & $1.01(1.01,1.02)$ & 0.0009 \\
\hline CVC & & & & & $1.21(1.03,1.42)$ & 0.0186 & $1.21(1.03,1.42)$ & 0.0205 \\
\hline Ever Diabetes & & & & & $1.30(1.15,1.47)$ & $<10^{-4}$ & $1.29(1.15,1.46)$ & $<10^{-4}$ \\
\hline Ever COPD & & & & & $0.99(0.80,1.22)$ & 0.9247 & $0.99(0.80,1.22)$ & 0.9194 \\
\hline $\begin{array}{l}\text { Five Year Median HH } \\
\text { Income (per } 1,000 \$ \text { ) }\end{array}$ & & & & & & & $1.00(1.00,1.00)$ & 0.8314 \\
\hline $\begin{array}{l}\text { Five Year Gini Coefficient } \\
(0 \text { to } 1)\end{array}$ & & & & & & & $2.84(0.11,70.90)$ & 0.5256 \\
\hline
\end{tabular}


be viable for up to $72 \mathrm{~h}$ [19]. On hard surfaces, disinfection with at least $70 \%$ ethanol, $0.5 \%$ hydrogen peroxide, or $0.0525 \%$ sodium hypochlorite (1:100 bleach) was shown to inactivate $\geq 99 \%$ of SARS-CoV-2 in most cases and at least inactivate $>90 \%$ of the virus [34]. Dialysis chair, arms, and all patient contact surfaces are covered by Medical Grade Vinyl (polyvinyl chloride-PVC) designed to withstand most disinfectants. Meticulous cleaning of chairs with 1:100 bleach between patients may have conferred protection to subsequent sitters. Although not tested specifically, it is possible our findings are applicable to potential transfer surfaces such as chairs in medical/dental offices, waiting rooms, airports, theaters, transports, and places of worship provided cleaning measures mimic those used in dialysis facilities.

Our study has several strengths including use of a comprehensive data set with documentation of SARSCoV-2 status and records of standard parameters of dialysis shifts, machines, and stations. A series of sensitivity analyses and a prospective analysis showed consistency across analyses. Overall, most facilities had 0 to 1 confirmed infected patient, which suggests within-center transmission of SARS-CoV-2 is low. For the primary analysis, we chose to use a case-control design given its suitability in studying rare events. In this analysis we traced backward 14 days to examine possible exposure from a 'shedding' SARS-CoV-2 patient who sat in the same chair immediately before the case or control. We also performed a secondary analysis to confirm the results using a prospective cohort design assessing the first chair in each facility occupied by a shedding SARS-CoV2 patient to investigate if the subsequent patient was infected. The prospective cohort design had as expected fewer cases, however, the results are consistent with the case-control design.

Our study has some limitations. We had no data to assess potential transmission in shared vehicle transport to facility. Since most facilities had only 0 or 1 infected patient, and since patients scheduled in similar shifts are usually transported together in shared personal or medical/public transport vehicles, infection during transport is not anticipated to have affected our results. Nonetheless, we cannot exclude the possibility of confounding due to the transmission of SARS-CoV-2 during transportation. Second, our analysis considers only symptomatic patients. Therefore, we cannot exclude the possibility of transmission from asymptomatic carriers who never developed symptoms that warranted RT-PCR testing. While asymptomatic spread is possible, individuals who remain asymptomatic throughout their entire course of SARS-CoV-2 infection are typically $>30$ years younger than the average dialysis patient, who is usually in the mid-sixties, and the secondary attack rate among asymptomatic carriers is generally lower than symptomatic carriers [35-37]. Finally, while we believe the fidelity of linking a specific dialysis machine to a specific chair was maintained, and thus we could examine vertical transmission, we could not examine the potential for horizontal transmission during a single shift because the proximity of one station to another could not be ascertained by the available data. That said, stations are spaced apart, ideally 6 feet, and patients were required to wear masks, making the likelihood of such transmission low.

We also acknowledge that in these challenging times, occasional erroneous documentation of station numbers linked to dialysis machines may have occurred. However, based on our findings, we consider vertical spread of SARS-CoV-2 in hemodialysis facilities unlikely, and that like studies examining transmission among hospital workers, household and restaurant contacts represent a more important site of spread [38]. Lastly, our data do not allow us to assess the possibility of vertical transfer between shift with staff members serving as vectors.

\section{Conclusions}

In summary, in many dialysis facilities across the United States that continued to deliver lifesaving chronic hemodialysis treatments in the pandemic, our findings suggest SARS-CoV-2 transmission risk is low for patients occupying the same chair as someone likely shedding the virus. These results may have been due to the rigorous cleaning protocols that take place in between patients, which at this time appear suitable for infection control in the ongoing COVID-19 pandemic.

\section{Abbreviations}

BMI: Body mass index; COPD: Chronic obstructive pulmonary disease; COVID19: Coronavirus disease; CVC: Central venous catheter; ESKD: End-stage kidney disease; PUI: Persons under investigation; RT-PCR: Real-time reverse transcription polymerase chain reaction; SARS-CoV-2: Severe acute respiratory syndrome coronavirus 2

\section{Acknowledgements \\ This manuscript has been posted on the preprint server MedRxiv [39]. We would like to thank Vladimir M Rigodon for assistance with regulatory protocol composition.}

\section{Authors' contributions \\ Author contributions are as follows: Conceptualization: R.T., J.W., C.W., H.Z., L.R.F., L.U., K.B., Y.W., R.K., J.H., P.K., F.M.; Data curation: J.W., L.U.; Formal Analysis: C.W., Y.W.; Funding acquisition: R.T., Y.W., R.K., J.H., P.K., F.M.; Investigation: not applicable for use of secondary data; Methodology: R.T. J.W., C.W., H.Z., L.R.F., L.U., Y.W., P.K.; Project administration: R.T., J.L., L.U., Y.W., P.K.; Resources: Y.W., R.K., J.H., P.K., F.M.; Software: J.W., C.W., H.Z., Y.W.; Supervision: R.T., L.U., K.B., Y.W., R.K., J.H., P.K., F.M.; Validation: J.W., C.W., Y.W.; Visualization: J.W., C.W., J.L., H.Z., Y.W.; Writing - original draft: R.T., J.W., C.W., H.Z., L.R.F., L.U., Y.W., P.K., F.M.; Writing - review \& editing: R.T., J.W., C.W., J.L., H.Z., L.R.F., L.U., K.B., Y.W., R.K., J.H., P.K., F.M. All authors have approved this manuscript for publication.}

\section{Funding}

This study was supported by Fresenius Medical Care North America. The conduct of the formal analysis by University of California-Santa Barbara was supported in part by a grant from the National Institute of Diabetes and Digestive and Kidney Diseases (R01DK130067). 


\section{Availability of Data and Materials}

The dataset used for this analysis is not publicly available. The data utilized was obtained from the Fresenius Medical Care North America Knowledge Center Data Warehouse, which is restricted to use by only authorized employees of Fresenius Medical Care. The dataset was deidentified for the conduct of the formal analysis by C.W. and Y.W. Reasonable requests to access data may be considered under executed contractual agreements between Fresenius Medical Care North America and an external individual's institution; requests can be sent to author L.U.

\section{Declarations}

\section{Ethics approval and consent to participate}

This analysis was performed under a regulatory protocol that was reviewed by New England Institutional Review Board (Needham Heights, MA, United States; NEIRB WO\#: 17-1349084-1). The Institutional Review Board approved the protocol under an Exempt Category due to use of deidentified data that did not contain any Protected Health Information and informed consent (written or verbal) was not required or applicable per the United States Code of Federal Regulations (45 CFR 46.104-d4ii). Analysis was conducted in adherence with Declaration of Helsinki.

\section{Consent for publication}

Not applicable.

\section{Competing interests}

R.T. reports employment at Mass General Brigham; reports having consultancy agreements with Fresenius Medical Care, and Biogen Idec; reports receiving honoraria from Roche Diagnostics; reports ownership interests in Aggamin LLC; reports receiving research funding from the National Institutes of Health, Kaneka Corp, Diasorin, and ThermoFisher; reports having patents and invention interests that include ThermoFisher and Up-To-Date; reports being a scientific advisor to Aggamin LLC. J.W. reports employment at Fresenius Medical Care. J.L. reports employment at Fresenius Medical Care; reports being an inventor on patent in the field of dialysis; reports being a guest editor on the Editorial Board of Frontiers in Physiology. H.Z. reports employment at Renal Research Institute, a wholly owned subsidiary of Fresenius Medical Care. L.R.F. reports employment at Renal Research Institute, a wholly owned subsidiary of Fresenius Medical Care. L.U. reports employment at Fresenius Medical Care; reports having share options/ownership in Fresenius Medical Care; reports being an inventor on multiple patents in the field of dialysis. K.B. reports employment at Fresenius Medical Care; reports having share options/ownership in Fresenius Medical Care; reports being an inventor on patent in the field of dialysis. Y.W. reports receiving research funding from the National Institutes of Health and Fresenius Medical Care. R.K. reports employment at Fresenius Medical Care; reports having share options/ownership in Fresenius Medical Care. J.H. reports employment at Fresenius Medical Care; reports having share options/ ownership in Fresenius Medical Care; reports being an inventor on patent in the field of dialysis. P.K. reports employment at Renal Research Institute, a wholly owned subsidiary of Fresenius Medical Care; reports having share options/ownership in Fresenius Medical Care; reports being an inventor on multiple patents in the field of dialysis; reports being on the Editorial Board of Blood Purification and Kidney and Blood Pressure Research. F.M. reports employment at Fresenius Medical Care; reports having share options/ownership in Fresenius Medical Care; reports being an inventor on multiple patents in the field of dialysis; reports having directorships in Fresenius Medical Care Management Board, Goldfinch Bio, and Vifor Fresenius Medical Care Renal Pharma. All remaining authors have nothing to disclose.

\section{Author details}

${ }^{1}$ Mass General Brigham, Boston, MA, USA. ${ }^{2}$ Fresenius Medical Care, Global Medical Office, 920 Winter Street, Waltham, MA, USA. ${ }^{3}$ Carnegie Mellon University, Pittsburgh, PA, USA. ${ }^{4}$ Renal Research Institute, New York, NY, USA. ${ }^{5}$ Fresenius Kidney Care, Waltham, MA, USA. ${ }^{6}$ University of California-Santa Barbara, Santa Barbara, CA, USA. ${ }^{7}$ Fresenius Medical Care North America, Medical Office, Waltham, MA, USA. ${ }^{8}$ Icahn School of Medicine at Mount Sinai, New York, NY, USA. ${ }^{9}$ Fresenius Medical Care AG \& Co. KGaA, Global Medical Office, Bad Homburg, Germany.
Received: 13 May 2021 Accepted: 6 September 2021 Published online: 16 September 2021

\section{References}

1. Mehrotra R. Counterpoint: Twice-Weekly Hemodialysis Should Be an Approach of Last Resort Even in Times of Dialysis Unit Stress. Journal of the American Society of Nephrology. 2020;31(6):1143-4.

2. Staying Safe During Dialysis and the COVID-19 Outbreak [https://www. kidney.org/newsletter/staying-safe-during-dialysis-and-covid-19-outbreak]

3. Lenny Bernstein $C R$, Tom Hamburger: Dialysis patients are at high risk during covid-19 outbreak. In: Washington Post. vol. 2020; 2020.

4. Targher G, Mantovani A, Wang XB, Yan HD, Sun QF, Pan KH, Byrne CD, Zheng Kl, Chen YP, Eslam M et al: Patients with diabetes are at higher risk for severe illness from COVID-19. Diabetes Metab 2020

5. de Carvalho Sales-Peres SH, de Azevedo-Silva LJ, Bonato RCS, de Carvalho Sales-Peres M, da Silvia Pinto AC, Santiago Junior JF: Coronavirus (SARS-CoV2) and the risk of obesity for critically illness and ICU admitted: metaanalysis of the epidemiological evidence. Obes Res Clin Pract 2020.

6. Chawki S, Buchard A, Sakhi H, Dardim K, El Sakhawi K, Chawki M, Boulanger H, Kofman T, Dahmane D, Rieu P et al: Treatment Impact on COVID-19 evolution in hemodialysis patients. Kidney International 2020.

7. Pei YP, Greenwood CM, Chery AL, Wu GG. Racial differences in survival of patients on dialysis. Kidney Int. 2000;58(3):1293-9.

8. Immune dysfunction in uremia-an update. Toxins (Basel) 2012, 4(11): 962-990.

9. Nicholas SB, Kalantar-Zadeh K, Norris KC. Socioeconomic disparities in chronic kidney disease. Adv Chronic Kidney Dis. 2015;22(1):6-15.

10. Crews DC, Liu Y, Boulware LE. Disparities in the burden, outcomes, and care of chronic kidney disease. Curr Opin Nephrol Hypertens. 2014;23(3):298-305.

11. Coresh J, Selvin E, Stevens LA, Manzi J, Kusek JW, Eggers P, Van Lente F, Levey AS. Prevalence of chronic kidney disease in the United States. Jama. 2007;298(17):2038-47.

12. Kramer HJ, Saranathan A, Luke A, Durazo-Arvizu RA, Guichan C, Hou S, Cooper R. Increasing Body Mass Index and Obesity in the Incident ESRD Population. Journal of the American Society of Nephrology. 2006;17(5): 1453-9.

13. Cho JH, Kang SH, Park HC, Kim DK, Lee SH, Do JY, Park JW, Kim SN, Kim MS, Jin K et al: Hemodialysis with Cohort Isolation to Prevent Secondary Transmission during a COVID-19 Outbreak in Korea. J Am Soc Nephrol 2020.

14. Park HC, Kim DH, Yoo KD, Kim YG, Lee SH, Yoon HE, Kim DK, Kim SN, Kim MS, Jung YC et al: Korean clinical practice guidelines for preventing transmission of coronavirus disease 2019 (COVID-19) in hemodialysis facilities. Kidney Res Clin Pract 2020.

15. Jager KJ, Kramer A, Chesnaye NC, Couchoud C, Sanchez-Alvarez JE, Garneata L, Collart F, Hemmelder MH, Ambuhl P, Kerschbaum J et al: Results from the ERA-EDTA Registry indicate a high mortality due to COVID-19 in dialysis patients and kidney transplant recipients across Europe. Kidney Int 2020.

16. Fresenius Medical Care North America: COVID-19 Resource and Education Center [https://fmcna.com/company/covid-19-resource-center/]

17. Centers for Disease Control and Prevention: Things to Know about the COVID-19 Pandemic [https://www.cdc.gov/coronavirus/2019-ncov/your-hea Ith/need-to-know.html]

18. Islam MS, Rahman KM, Sun Y, Qureshi MO, Abdi I, Chughtai AA, Seale H: Current knowledge of COVID-19 and infection prevention and control strategies in healthcare settings: A global analysis. Infect Control Hosp Epidemiol 2020:1-11.

19. van Doremalen N, Bushmaker T, Morris DH, Holbrook MG, Gamble A, Williamson BN, Tamin A, Harcourt JL, Thornburg NJ, Gerber SI, et al. Aerosol and Surface Stability of SARS-CoV-2 as Compared with SARS-CoV-1. N Engl J Med. 2020;382(16):1564-7.

20. Wiersinga WJ, Rhodes A, Cheng AC, Peacock SJ, Prescott HC. Pathophysiology, Transmission, Diagnosis, and Treatment of Coronavirus Disease 2019 (COVID-19): A Review. JAMA. 2020;324(8):782-93.

21. Meyerowitz EA, Richterman A, Gandhi RT, Sax PE. Transmission of SARS-CoV2: A Review of Viral, Host, and Environmental Factors. Ann Intern Med. 2021; 174(1):69-79.

22. Ortiz-Prado E, Simbaña-Rivera K, Gómez-Barreno L, Rubio-Neira M, Guaman LP, Kyriakidis NC, Muslin C, Jaramillo AMG, Barba-Ostria C, Cevallos-Robalino $D$, et al. Clinical, molecular, and epidemiological characterization of the SARS-CoV-2 virus and the Coronavirus Disease 2019 (COVID-19), a 
comprehensive literature review. Diagn Microbiol Infect Dis. 2020;98(1): 115094-115094.

23. Guidance Regarding Methods for De-identification of Protected Health Information in Accordance with the Health Insurance Portability and Accountability Act (HIPAA) Privacy Rule. US Department of Health \& Human Services; : (Last Accessed 09 Jul 2021) https://www.hhs.gov/hipaa/forprofessionals/privacy/special-topics/de-identification/index.html\#standard.

24. Centers for Disease Control and Prevention: Coronavirus Disease 2019 (COVID-19) Outpatient Dialysis Facility Preparedness Assessment Tool [https://www.cdc.gov/coronavirus/2019-ncov/downloads/COVID-19-outpa tient-dialysis.pdf]

25. Breslow NE. Statistics in Epidemiology: The Case-Control Study. Journal of the American Statistical Association. 1996;91(433):14-28.

26. Cheng HY, Jian SW, Liu DP, Ng TC, Huang WT, Lin HH, Taiwan C-OIT. Contact Tracing Assessment of COVID-19 Transmission Dynamics in Taiwan and Risk at Different Exposure Periods Before and After Symptom Onset. JAMA Intern Med. 2020;180(9):1156-63.

27. Wei WE, Li Z, Chiew CJ, Yong SE, Toh MP, Lee VJ: Presymptomatic Transmission of SARS-CoV-2 - Singapore, January 23-March 16, 2020. MMWR Morb Mortal Wkly Rep 2020, 69(14):411-415.

28. Arons MM, Hatfield KM, Reddy SC, Kimball A, James A, Jacobs JR, Taylor J, Spicer K, Bardossy AC, Oakley LP, et al. Presymptomatic SARS-CoV-2 Infections and Transmission in a Skilled Nursing Facility. N Engl J Med. 2020; 382(22):2081-90.

29. Roncon L, Zuin M, Rigatelli G, Zuliani G. Diabetic patients with COVID-19 infection are at higher risk of ICU admission and poor short-term outcome. J Clin Virol. 2020;127:104354.

30. Adler NE, Stewart J. Health disparities across the lifespan: meaning, methods, and mechanisms. Ann N Y Acad Sci. 2010;1186:5-23.

31. Kennedy BP, Kawachi I, Glass R, Prothrow-Stith D. Income distribution, socioeconomic status, and self rated health in the United States: multilevel analysis. BMJ. 1998;317(7163):917-21.

32. American Community Survey, 2018 American Community Survey 5-Year Estimates, Table B19083: Gini Index of Income Inequality US Census Bureau: Obtained from: data.https:/data.census.gov/cedsci/; (last accessed 06 Jul 2021).

33. American Community Survey, 2018 American Community Survey 5-Year Estimates, Table: S1903 MEDIAN INCOME IN THE PAST 12 MONTHS (IN 2018 INFLATION-ADJUSTED DOLLARS). US Census Bureau:Obtained from: data. census.gov; https://data.census.gov/cedsci/; (last accessed 06 Jul 2021).

34. Meyers C, Kass R, Goldenberg D, Milici J, Alam S, Robison R: Ethanol and Isopropanol Inactivation of Human Coronavirus on Hard Surfaces. J Hosp Infect 2020.

35. Buitrago-Garcia D, Egli-Gany D, Counotte MJ, Hossmann S, Imeri H, Ipekci AM, Salanti G, Low N. Occurrence and transmission potential of asymptomatic and presymptomatic SARS-CoV-2 infections: A living systematic review and meta-analysis. PLoS Med. 2020;17(9):e1003346.

36. Kronbichler A, Kresse D, Yoon S, Lee KH, Effenberger M, Shin Jl. Asymptomatic patients as a source of COVID-19 infections: A systematic review and meta-analysis. Int J Infect Dis. 2020;98:180-6.

37. Rincon A, Moreso F, Lopez-Herradon A, Fernandez-Robres MA, Cidraque I, Nin J, Mendez O, Lopez M, Pajaro C, Satorra A, et al. The keys to control a COVID-19 outbreak in a haemodialysis unit. Clin Kidney J. 2020;13(4):542-9.

38. Steensels D, Oris E, Coninx L, Nuyens D, Delforge ML, Vermeersch P, Heylen L. Hospital-Wide SARS-CoV-2 Antibody Screening in 3056 Staff in a Tertiary Center in Belgium. JAMA. 2020;324(2):195-7.

39. Thadhani R, Willetts J, Wang C, Larkin J, Zhang H, Fuentes LR, Usvyat L, Belmonte K, Wang Y, Kossmann R et al: Transmission of SARS-CoV-2 Considering Shared Chairs in Outpatient Dialysis: A Real-World Case-Control Study. medRxiv 2021:2021.2002.2020.21251855.

\section{Publisher's Note}

Springer Nature remains neutral with regard to jurisdictional claims in published maps and institutional affiliations.

Ready to submit your research? Choose BMC and benefit from:

- fast, convenient online submission

- thorough peer review by experienced researchers in your field

- rapid publication on acceptance

- support for research data, including large and complex data types

- gold Open Access which fosters wider collaboration and increased citations

- maximum visibility for your research: over $100 \mathrm{M}$ website views per year

At BMC, research is always in progress.

Learn more biomedcentral.com/submissions 